\title{
A Clinical Study on Epidemiology and Management of Incisional Hernia
}

\author{
Sanjeeva Raju Kunche ${ }^{1}$, Chetan Kumar A. ${ }^{2}$ \\ ${ }^{1}$ Department of General Surgery, Sri Venkateshwaraa Medical College and Research \\ Centre, Ariyur, Pondicherry, India. ${ }^{2}$ Department of General Surgery, Sri Venkateshwaraa \\ Medical College and Research Centre, Ariyur, Pondicherry, India.
}

\section{ABSTRACT}

\section{BACKGROUND}

Incisional hernia is one of the common complications encountered following abdominal surgery and is an important cause of morbidity. It can be repaired by following anatomical, mesh or laparoscopic methods. The incidence of these hernias is high even with recent advances in surgery, anaesthesiology, antibiotics, and suture materials used. We wanted to study the epidemiology, aetiology, mode of presentations, modalities of treatment and its outcome, of incisional hernia.

\section{METHODS}

This study was done from July 2017 and June 2019, 50 patients with incisional hernia who got admitted in the Department of Surgery at Sri Venkateshwaraa Medical College and Research Center, Ariyur were subjected to anatomical or mesh repair depending on the surgeon's choice and size of defect. A total of 50 cases were studied and followed for a period of 6- to 18-months. Patients of age 12 years and above of both sexes who presented with incisional hernia post abdominal surgery were included in this study. Age below 12 years and those presented with other hernias like inguinal/ventral hernias were excluded. Data was collected and analysed by various statistical methods.

\section{RESULTS}

Incisional hernia was found to be the second most common type of hernia. The incidence was more common in females, who underwent gynaecological procedures by lower midline incisions. It was found to be more common in the age group 30-60 years. Predominant risk factors being wound infection and obesity. Infraumbilical midline incision (50\%) was found to be more common compared to other incisions. Majority of patients who underwent emergency surgery developed incisional hernia. Postoperative complications noted were mainly due to wound infections and seroma.

\section{CONCLUSIONS}

Mesh repair results in less recurrence than anatomical repair for incisional hernia. The incidence of incisional hernia is more common in women than men due to abdominal wall weakness secondary to multiple pregnancies, increased number of caesarean sections and gynaecological surgeries. Sterile aseptic technique and appropriate use of pre-operative antibiotics is necessary to reduce the occurrence of incisional hernia.

\section{KEY WORDS}

Incisional Hernia, Anatomical Repair, Mesh Repair, Hernia Defect, Complications.
Corresponding Author: Dr. Sanjeeva Raju Kunche, No. 202, A-Block, 2nd Floor, Sri Venkateshwaraa Medical College \& Research Centre, Ariyur, Pondicherry-605009, India. E-mail: sanjeev2001jipmer@yahoo.com

DOI: $10.14260 /$ jemds/2020/98

Financial or Other Competing Interests: None.

How to Cite This Article:

Kunche SR, Kumar CA. A clinical study on epidemiology and management of incisional hernia. J. Evolution Med. Dent. Sci. 2020;9(07):433-436, DOI: $10.14260 /$ jemds/2020/98

Submission 11-12-2019,

Peer Review 22-01-2020,

Acceptance 28-01-2020,

Published 17-02-2020. 


\section{BACKGROUND}

Incisional hernia is defined as any abdominal wall defect with or without swelling in the area of a postoperative scar palpable by clinical examination or imaging. ${ }^{1}$ Every year there are approximately 4 million abdominal operations are being performed and the reported incidence of incisional hernia following abdominal surgery ranges from 11-20\%.2 Unlike other abdominal wall hernias, which occur through anatomical points of weakness, incisional hernias occur through a weakness at the site of abdominal wall closure. ${ }^{3}$ The incidence of these hernias is high even with the recent advances in surgery, anaesthesiology, antibiotics, suture materials used. Incidence of incisional hernia is next to inguinal hernia and may be higher than reported, since most of them are asymptomatic. Among abdominal incisions, highest incidence is found with lower midline abdominal incisions because it is through this incision most of the gynaecological and lower abdominal surgeries are being done. The postulated predisposing factors for incisional hernia are obesity, diabetes mellitus, steroids, smoking, suboptimal surgical technique, old age, malnutrition, multiple laparotomies, chronic pulmonary disease, type of incision and closure including suture material used and the most important wound infection. ${ }^{4}$ The pressure in the lower abdomen is more than upper abdomen and the posterior rectus sheath is deficient below umbilicus, any stress and strain on lower abdomen predisposes to hernia formation. Among the various etiological factors responsible for incisional hernias, raised intra-abdominal pressure and postoperative wound infections were found to be most common causes. So while planning surgery for the repair of incisional hernias utmost care should be taken in selecting the method of repair, suture material and Mesh used for preventing further recurrence. There are various methods used for repair of incisional hernias like anatomical repair, onlay mesh pair, laparoscopic repair etc. After Usher reported his experience with use of polypropylene suture, Prolene mesh, modern era of prosthetic hernia repair began in 1958 being widely used for wide defects in incisional hernias with considerably good results.5,6 Laparoscopic techniques of hernia repair have revolutionised the treatment of incisional hernia repair by reducing the morbidity and less hospital stay. Advantages of laparoscopic incisional hernia repair are no re-incision, less painful, safe, speedy recovery and less recurrence. ${ }^{7}$ Present study aims to assess and analyse various factors leading to development of Incisional hernias, postoperative complications, different modalities of surgical repair and their outcomes.

\section{METHODS}

The study was a retrospective study and study group was patients admitted in Sri Venkateshwaraa medical College and Research Center from July 2017 to June 2019. Institutional ethical committee approval was obtained, informed and written consent was taken from the patients. Out of 235 cases of various types of hernias operated a total of 50 cases of incisional hernias were studied and followed for a period varied from 6 months to 18 months. Patients of age 12 years and above of both sexes who presented with incisional hernia post abdominal surgery were included in this study. Age below 12 years and those presented with other hernias like inguinal/ ventral hernias were excluded. In this series patients admitted in surgical wards under all surgical units were examined to assess the abdominal wall defects, etiological and predisposing factors. A detailed case history and thorough clinical examination was done to determine the type and cause of hernia and necessary investigations were done according to proforma. After detailed physical examination of patients, clinical diagnosis was established including the associated etiological and predisposing factors. A final decision was made regarding method of repair to be done individually for every case depending on the need of surgery. Fifty cases underwent surgery and patients were preoperatively prepared to be medically fit to withstand the surgery. All cases were evaluated to look for immediate and late postoperative complications. Data was analysed to find out predisposing factors, advantage of various operative techniques, complications developed, need of good postoperative care and outcome of the various operations done.

\section{Statistical Analysis}

The statistical analysis was done by using SPSS software version 10.0 was used. Data was analyzed descriptively and tabulated using mean and standard deviation.

\section{RESULTS}

During the period of our study, a total of 235 patients have been operated for various types of hernia, out of these 50 cases were incisional hernia. Inguinal hernia was most common type accounting for $59.5 \%$, next common hernia was incisional hernia $(21.2 \%)$ remaining rare type of hernias constituting $19.2 \%$ of total cases studied. (refer table-1).

\begin{tabular}{|c|c|c|}
\hline Type & No. of Cases & Percentage \\
\hline Inguinal & 140 & 59.5 \\
\hline Incisional & 50 & 21.2 \\
\hline Femoral & 10 & 4.2 \\
\hline Umbilical & 14 & 6.0 \\
\hline Paraumbilical & 13 & 5.5 \\
\hline Epigastric & 8 & 3.5 \\
\hline Total Table 1. Incidence of Incisional Hernia \\
\hline \multicolumn{2}{|c}{} \\
\hline
\end{tabular}

Maximum number of cases in middle age group (30-60 yrs.) constituting $80 \%$ (refer table-2).Incisional hernia was found to be more common in females with male female ratio of $1: 2.3$.

\begin{tabular}{|c|c|c|}
\hline Age & No. of Patients & Percentage \\
\hline $12-20$ & 1 & 2 \\
\hline $21-30$ & 1 & 2 \\
\hline $31-40$ & 10 & 20 \\
\hline $41-50$ & 16 & 32 \\
\hline $51-60$ & 14 & 28 \\
\hline $61-70$ & 5 & 10 \\
\hline $71-80$ & 3 & 6 \\
\hline Total & $\mathbf{5 0}$ & $\mathbf{1 0 0}$ \\
\hline \multicolumn{2}{|c|}{ Table 2. Age Wise Incidence of Incisional Hernia } \\
\hline
\end{tabular}

Incisional hernia occurred in $24 \%$ of cases in the first postoperative year, about $50 \%$ of cases occurred in 2 nd to 4 th postoperative year, $26 \%$ of cases developed incisional 
hernia after 4th postoperative year. Obesity and anaemia were the most common predisposing factors. Chronic bronchitis, asthma, diabetes were less common etiological factors (refer table-3).

\begin{tabular}{|c|c|c|}
\hline Findings & No. of Cases & Percentage \\
\hline Obesity & 19 & 38 \\
\hline Anaemia & 21 & 42 \\
\hline Diabetes mellitus & 7 & 14 \\
\hline Hypertension & 7 & 14 \\
\hline Bronchial asthma & 4 & 8 \\
\hline Chronic bronchitis & 2 & 4 \\
\hline \multicolumn{2}{|c|}{ Table 3. Predisposing Factors } \\
\hline
\end{tabular}

Majority of patients who underwent emergency surgery developed incisional hernia (refer table-4), Gynaecological surgeries were the most common cause for incisional hernias accounting for $70 \%$ of the cases. (refer table-5).

\begin{tabular}{|c|c|c|}
\hline Nature & Number of Cases & Percentage \\
\hline Emergency & 29 & 58 \\
\hline Elective & 21 & 42 \\
\hline Total & $\mathbf{5 0}$ & $\mathbf{1 0 0}$ \\
\hline \multicolumn{3}{|c|}{ Table 4. Nature of Operation } \\
\hline
\end{tabular}

\begin{tabular}{|c|c|c|}
\hline Cause & Number of Cases & Percentage \\
\hline Abdominal hysterectomy & 12 & 24 \\
\hline Abdominal sterilization & 10 & 20 \\
\hline Caesarean section (LSCS) & 12 & 24 \\
\hline Acute intestinal obstruction & 1 & 2 \\
\hline Appendicular perforation & 4 & 8 \\
\hline Duodenal perforation & 6 & 12 \\
\hline Ileal perforation & 1 & 2 \\
\hline Epigastric hernia & 1 & 2 \\
\hline Ovarian cystectomy & 1 & 2 \\
\hline Open cholecystectomy & 2 & 4 \\
\hline \multicolumn{2}{|c|}{ Total } & $\mathbf{5 0}$ \\
\hline
\end{tabular}

Infraumbilical midline incision $(50 \%)$ was found to be more common compared to other incisions (refer table-6) Wound infection (18\%) and wound dehiscence (32\%) were found to be more common postoperative complications after previous surgeries. Only 6 cases were repaired by anatomical repair. Most of the cases have been repaired by onlay mesh repair. Out of 50 cases studied, 15 had complications, wound seroma is most common complication accounting for $20 \%$ and is more common in Prolene mesh repair than anatomical repair.

\begin{tabular}{|c|c|c|}
\hline Type & Number of Cases & Percentage \\
\hline Infraumbilical & 25 & 50 \\
\hline Supraumbilical & 11 & 22 \\
\hline Mid Midline & 1 & 2 \\
\hline Right paramedian & 1 & 2 \\
\hline Pfannenstiel & 12 & 24 \\
\hline Total & $\mathbf{5 0}$ & $\mathbf{1 0 0}$ \\
\hline \multicolumn{2}{|c|}{ Table 6. Incision Used in Previous Surgeries } \\
\multicolumn{2}{|l}{}
\end{tabular}

\section{DISCUSSION}

The incidence of Incisional hernia in this study was $21.2 \%$ which was second only to inguinal hernia (59.5\%). According to a study done by Mutwali et al ${ }^{8}$ the incidence was $11-20 \%$ which was slightly lesser when compared to the present study. Incisional hernia is a common complication due to patient or wound related factors in spite of the good technique adopted by the surgeons.
In the present study the most common group involved was 40 - 50 years (32\%) with male to female ratio was 1:2.3. Ellis et $\mathrm{al}^{9}$ in their study reported that $48 \%$ of patients developing incisional hernia belonged to the age group of 31 40 years with male to female ratio $4.8: 1$. In the study by Agrawal et $\mathrm{al}^{10}{ }^{10}$ male to female ratio was $1: 1.6$. The incidence of female patients with incisional hernia in this study was $70 \%$ which was higher than the study done by Millbourn et $a^{11}$ whose incidence was $64.6 \%$. The reason for higher incidence of incisional hernia in females in this study could be due to increased incidence of gynaecological surgeries and weakness of abdominal muscles in women due to multiple pregnancies. In the present study obesity and anaemia were the most common predisposing factors, chronic bronchitis, asthma, diabetes were less common factors. Obese patients were adviced weight reduction and abdominal exercises to increase the tone of abdominal muscles. Anaemia was corrected with blood transfusion and iron infusion. Obesity has been described as one of the main aetiological factors in incisional hernia. In the present series $38 \%$ of patients are moderate to extremely obese. In Shouldice study, $87 \%$ were obese and in Agbakwuru's study ${ }^{12} 27.3 \%$ were obese. Obesity was associated with a threefold increase in herniation in Bucknell's study. In a study done by Bose et al ${ }^{13}$ which documented the common risk factors as wound infection in $53.63 \%$ of cases, obesity in $30 \%$ and COPD in $20.9 \%$. In the study done by Agrawal et al, ${ }^{10}$ most common cause for incisional hernia was found to be postoperative infection (47\%), followed by cough (10\%) and early return to work $(2 \%)$. In the present study risk factors promoting incisional hernias were wound infection accounted for $40 \%$, Obesity in $30 \%$ and COPD in $8 \%$ of cases.

In the present study incisional hernia occurred in $24 \%$ of cases in the first postoperative year, about $50 \%$ of cases occurred in 2 nd to 4 th postoperative year, $26 \%$ of cases developed incisional hernia after 4 th postoperative year, compared with study done by Bucknell et al,7 42\% patients of presented with incisional hernia 1-5 years after primary surgery and around $68 \%$ patients who had lower midline abdominal incisions developed incisional hernia followed by $18 \%$ patients with upper midline incision, $10 \%$ patients with right paramedian and $4 \%$ patients with left paramedian incisions. Similarly, Millbourn et al ${ }^{11}$ and Carlson ${ }^{14}$ also found that this type of hernia is common in females undergoing gynecological surgeries in which lower abdominal incisions are made. In this study $52 \%$ of the incisional hernia occurred over lower midline incisions this could be due to raised intraabdominal hydrostatic pressure in lower abdomen compared to upper abdomen and due to absence of posterior rectus sheath below arcuate line. This incision is commonly used in gynaecological surgeries where patients may already have poor abdominal wall musculature. In the present study Wound infection (18\%) and wound dehiscence (32\%) were found to be more common postoperative complications after previous abdominal surgeries. In several studies wound infection following surgery was the main factor for the development of incisional hernia. Out of 50 cases studied, 15 had complications, wound seroma is the most common complication accounting for $20 \%$ and is more common in Prolene mesh repair than anatomical repair.

Khaira H.S et $\mathrm{al}^{15}$ reported seroma formation in 6 out of 35 patients and wound infection in 1 out of 35 patients. In a 
study done by Tulaskar et al 169 cases (14\%) had surgical site infection, 4 cases $(6.25 \%)$ had seroma formation and 2 cases (3.1\%) had wound gaping. In this study 4 methods were used for the repair of incisional hernia among which polypropylene mesh repair was used in $63 \%$ of patients, laparoscopic hernia repair (17\%), double breasting method $(12 \%)$ and anatomical repair (8\%). In the present study there were no recurrences until 18 months of follow up. Usher 6 reported zero percent recurrence in 48 patients who were treated by polypropylene mesh repair. Jacobus W. A et al ${ }^{17}$ reported a 10 year cumulative rate of recurrence of $63 \%$ in anatomical repair and $32 \%$ in mesh repair. The recurrence rate may vary according to the method of repair, but majority of studies recommend mesh repair to decrease the recurrence rate. Jenkins ${ }^{18}$ reported in their study of 154 patients, established the superiority of mesh repair over anatomical repair with regard to recurrence of hernia.

\section{CONCLUSIONS}

Incisional hernia is more common in women than men due to abdominal wall weakness secondary to multiple pregnancies, increased number of caesarean sections and gynaecological surgeries. Infraumbilical midline incisions should be restricted to the surgeries where access to the lower abdomen and pelvis organs is a must. Sterile aseptic technique and appropriate use of pre-operative antibiotics is necessary to reduce the occurrence of incisional hernia. Suction drains must be used in both anatomical and mesh repairs to reduce the post-operative complications like seroma, wound infection and wound gapping, thereby reducing the recurrence of incisional hernia. Mesh repair has less rate of recurrence when compared to anatomical repair; hence, mesh repair should be preferred over anatomical repair. Laparoscopic hernia repair should be the first line of treatment for recurrent incisional hernias.

\section{REFERENCES}

[1] Korenkov M, Paul A, Sauerland S, et al. Classification and surgical treatment of incisional hernia. Langenbeck's Arch Surg 2001;386 (1):65-73.

[2] Williams NS, Bulstrode CJ, Oconnell PR. Bailey and Love's Short practice of surgery. Abdominal wall hernia. $25^{\text {th }}$ edn. UK: Hodder Arnold Publisher 2008: p. 986-9.
[3] Sanders DL, Kingsnorth AN. The modern management of incisional hernias. BMJ 2012;344:e2843.

[4] Anthony T, Bergen PC, Kim LT, et al. Factors affecting recurrence following incisional herniorrhaphy. World J Surg 2000;24 (1):95-101.

[5] Dixon CF. Repair of incisional hernia. Surg Gynecol Obstet 1929;48:700-1.

[6] Usher FC. Hernia repair with knitted polypropylene mesh. Surg Gynecol Obstet 1963;117:239-40.

[7] Bucknall TE, Cox PJ, Ellis H. Burst abdomen and incisional hernia: a prospective study of 1129 major laparotomies. Br Med J 1982;284 (6320):931-3.

[8] Mutwali IM. Incisional hernia: risk factors, incidence, pathogenesis, prevention and complications. Sudan Med Monit 2014;9 (2):81-6.

[9] Ellis H, Gajraj H, George CD. Incisional hernias: When do they occur? Br J Surg 1983;70 (5):290-1.

[10] Agrawal M, Singh H, Sharma SP, et al. Prevalence, clinical presentation, and management of incisional hernia in the Indian population: a cross-sectional study. Int J Sci Stud 2016;4 (7):51-54.

[11] Millbourn D, Cengiz Y, Israelsson LA. Effect of stitch length on wound complications after closure of midline incisions: a randomized controlled trial. Arch Surg 2009;144 (11):1056-9.

[12] Agbakwuru EA, Olabanji JK, Alatise OI, et al. Incisional hernia in women: predisposing factors and management where mesh is not readily available. Libyan J Med 2009;4 (2):66-9.

[13] Bose SM, Roshan L, Manju K, et al. Ventral hernia-a review of 175 cases. Indian Journal of Surgery 1999;61 (3):180-4.

[14] Carlson MA. New developments in abdominal wall closure. Chirurg 2000;71 (7):743-53.

[15] Khaira HS, Lall P, Hunter B, et al. Repair of incisional hernias. J R Coll Surg Edinb 2001;46 (1):39-43.

[16] Tulaskar N, Nichkaode P, Dasgupta S, et al. Clinical study and management of incisional hernia by onlay or preperitoneal mesh repair: a prospective study in rural set up. International Journal of Biomedical and Advance Research 2013;4 (5):328-34.

[17] Jacbus WA. Surgical management of large incision hernias by an intraperitoneal polypropylene. Surge Gynecol Obstet 1998;165:204-6.

[18] Jenkins TP. The burst abdominal wound: a mechanical approach. Br J Surg 1976;63 (11):873-6. 